\title{
How to Become a Manufacturing Cell Fully-Automated Without Robots: Case-Study in the Automotive Components Industry
}

\author{
F J G Silva*, W Araujo, R D S G Campilho, A Baptista and G Pinto \\ Department of Mechanical Engineering, School of Engineering, Portugal
}

Received: 阱 September 08, 2018; Published: 制 September 11, 2018

*Corresponding author: F J G Silva, Department of Mechanical Engineering, School of Engineering, Portugal

\begin{abstract}
Productivity is a key factor for companies manufacturing parts and sets to the automotive industry. Automation plays an important role in this matter, allowing development of entire manufacturing cells without the direct need of workers. Even in countries where the labour cost is relatively low, it becomes necessary to improve the level of automation applied to manufacture cells and reduce the dependence of the human labour unpredictability, also increasing the quality and reducing the costs. This case study was developed based on an industrial request in order to improve a semi-automatic cell devoted to seat suspension mat manufacturing. The original cell allows several automatic operations but it needs two workers for two specific operations not considered in the initial design. Thus, new concepts of wire feeding and manipulation were developed in order to allow a better material flow throughout the cell. The new cell was designed and built with success, allowing obtain a fully-automated system, which leads to a better productivity and reliability of the manufacturing process.
\end{abstract}

Keywords: Fully-Automated Cells; Labour Reduction; Automation Without Robots; Seat Suspension-Mat; Automotive Industry; Mechanical Engineering

\section{Introduction}

The competitiveness that is inherent in the automotive industry has and always had a dynamic behaviour. However, there has been, over the last century, the adoption of different strategies, from craft production to mass production of Henry Ford, through the brand policy and the variety of Sloan products, the lean production (lean manufacturing) and more recently to build-to-order initiatives. These changes are not only common to the major producers of vehicles, but were also observed in luxury car producers, seen as artisan producers [1]. The car mass production was a strategy adopted in the automotive industry and started with Henry Ford, founder of "Fordism", a working model that boiled down to mass produce cars at low cost [2,3]. Today's consumer wants to influence and participate in the product design, which led to a new paradigm of production strategy. Therefore, at its early stages, the automotive industry had in the market unique models that had a small variety of features, such as the Ford $\mathrm{T}$ and Volkswagen Beetle, but in nowadays manufacturing, organizations must be flexible and be able to comprise a long product variety to remain competitive [4].

Indeed, companies must be able to adapt to the market constant changes [5,6].

The value chain related to the automotive industry presents a high degree of complexity $[7,8]$. A typical supply chain includes car manufacturer (OEM's-Original Equipment Manufacturers), final components or subassemblies suppliers (Tier 1, 2 and 3), distributors, retailers and customers. The OEM's are constantly looking for suppliers to whom they can delegate responsibilities in areas such development, sourcing and planning, and this constant search induces pressures in the suppliers to lower prices and make deliveries within the stipulated deadlines, without compromising the products quality assurance. Indeed, quality and delivery time are indicators that highly affect the evaluation of the preferred product supplier $[7,9]$. In the specific case of the car seat, the evolution from mass to a personalized production, according to customer needs can also be applied. Following the evolution of automobile production, the seat was traditionally produced as an integral part of the automobile, where the available possible configurations were 
limited or null. With the increasing requirements of customers, this behaviour has changed along the times. With these new realities, the seat became an important element, with different configurations and new component options. The driver can now benefit from a seat with more comfort, extra features or have the possibility of seat heating. Once again, companies must follow the trend of the product variety.

This variety of products can affect the delivery time, which plays an important role in competitiveness. The delivery time can be compromised if a product is standardized or customized, with a shorter time delivery for the first case and longer for the second. Companies thus have the option to choose to reduce the delivery time, engaging in standard products, but companies with customized products must be able to meet the delivery time by means of increased flexibility for customized products [10]. An example to optimize the delivery time was presented in the paint line of the Toyota Motor Manufacturing's Georgetown plant, where an electronic signal is sent to seat supplier within the information of the customized seat of the car that is present in the assembly line. The seat supplier should manufacture and deliver the seat exactly where it is installed at the Toyota assembly line [11].

A number of industries have been found to be clearly capitalintensive and a number of others clearly labour-intensive [12]. In the last thirty years, many companies located in industrialized countries have been centralized their efforts by upgrading the technological level of their production lines to keep in competition with countries where the production costs are lower, due to low labour costs (non-industrialized countries). This resulted in companies in industrialized countries to migrate from the labour to the capital-intensive model [13]. In some way, a company can be rated in accordance with the amount of capital or labour. If, in one hand, a company with a capital-intensive model has high levels of automation in detriment of hand labour, on the other hand, a labour intensive model usually uses a high amount of hand labour [14].

The automotive industry is not an exception of this classification model and neither of this behaviour. Although the automotive sector involves a high number of hand labour operations [15], and at the same time high automation rates, some companies in less developed countries, is fairly automated and use an intensive hand labour to decrease production costs, although in the industrialized world the manufacturing companies use highly automated and robotized systems. Thus, in general, the automotive sector adopts a capital-intensive model, due to the constant seek for an automated production process. Furthermore, manual assembly lines usually congregate in a complex number of relationships often difficult to study and understand [16,17].

As described before, the customer is an important player in the value chain, and wants his requirements fulfilled. As a consequence, the companies must be in constant changes due to market variations, and to adopt new processes and production technologies using mainly automation $[18,19]$. Independently of the technologies involved in this process, must of the times companies use automation and robotics systems to increase their competitiveness and productivity, ensuring as well as high levels of quality and repeatability [20]. Automation and robotics, apart from playing an important role in ergonomic problems [21], also help companies to increase productivity and flexibility, despite of some conflicts between these features. Indeed, production and assembly line with high levels of productivity tend to be dedicated and not a flexible system. The automotive industry is endowed with very similar products that can be assembled in the same production line with minor adjustments they adapt their lines. With automation a company is able to reduce the setup time, increase the productivity, improve assembly accuracy, and reduce the human operations [22].

\section{Case Study}

\section{Scope}

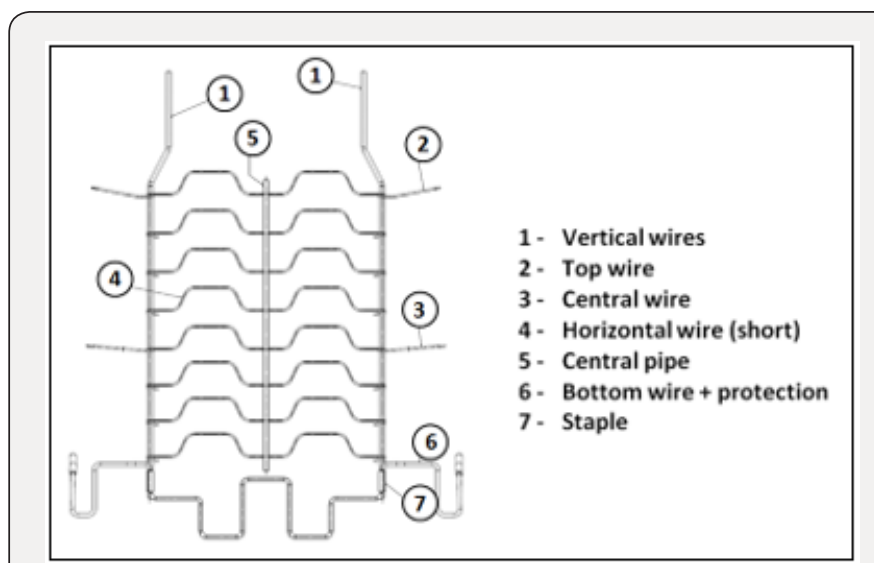

Figure 1: Suspension mat-main components.

Among various elements that comprise the car configuration, the seat is seen as a key element in the safety and comfort of the driver and remaining passengers. The seat is the element that connects the occupants to the vehicle and plays a key role in security in the event of an accident or sudden manoeuvres, keeping the driver attached to the vehicle frame [23]. This case study was performed on a production line that manufactures a specific component for car seats. The company where the line is installed is dedicated to the production of automobile systems and components. The line is responsible for the manufacturing and assembly of one of several products of the same family, the "Suspension Mat". Suspension mat is composed by several components obtained by spring steel wire, which vary their geometry and size (Figure 1). Suspension mat support foams either the seat or backrest and is a component that gives the desirable flexibility to the car seat, being as well an element that helps the vibrations absorption from the vehicle structure to the occupants. These features work together aiming to increase the comfort. A brief introduction to the main operations present in the product original process is made in Table 1 . Therefore, in order 
to understand the configuration of the original suspension mat production line, a process layout is presented in Figure 2. A brief overview of process layout is made

Table 1: Main operations of suspension line production line.

\begin{tabular}{|c|c|c|}
\hline Workstation & Main operation & \\
\hline 1 & Vertical wires & Production of vertical wires \\
\hline 2 & Spine & Assembly of the central body \\
\hline 3 & Winding & $\begin{array}{c}\text { Winding of the central wires } \\
\text { around vertical wires }\end{array}$ \\
\hline 4 & Castel & Deformation of central wires \\
\hline 5 & Hook & $\begin{array}{c}\text { Winding of hooks on central } \\
\text { wires }\end{array}$ \\
\hline 6 & Staples & Assembly of bottom wire \\
\hline 7 & Packaging & Packaging of final product \\
\hline
\end{tabular}

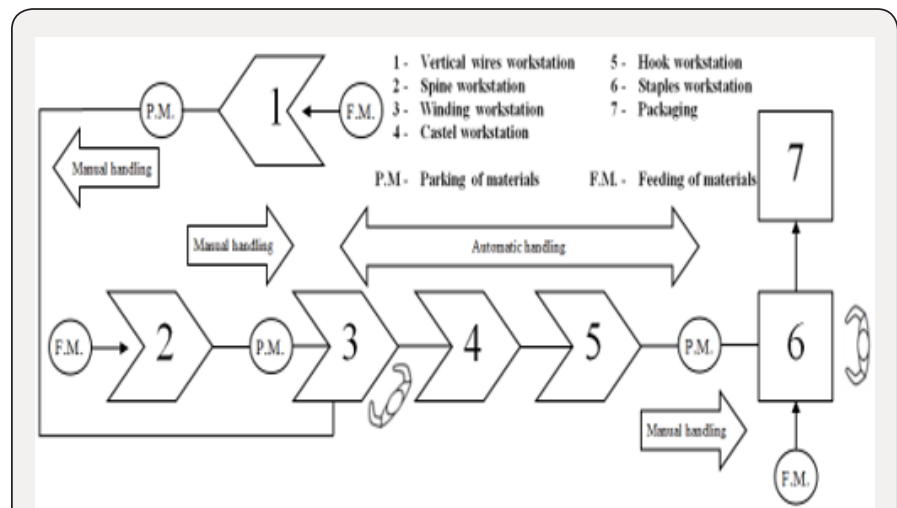

Figure 2: Initial process layout of the suspension mat production line.

a) Seven workstations - two of them require human labour to accomplish the final operations (winding and staples workstations), the others five workstations are fully automated.

b) Handling operations - manual handling between several workstations (vertical wires and winding workstation; spine and winding workstation; hook and staples workstation), automatic handling between the winding, castle and hook workstations

Regarding the initial scenario, the suspension mat production line has an inefficient configuration. If, on one hand, the spine and vertical workstation are located in a less favourable area, on the other hand, the cycle time highly varies due to the manual operations (assembly and handling). Apart from this, the layout line configuration is inappropriate to the flow of the suspension mat assembly as well. Although the line has automatic operations, it requires, besides manual handling and assembly between some workstations to complete components, feeding operations of raw materials. Due to these facts, the suspension mat assembly cycle time has an irregular behaviour that affect the process flow. The continuous intervention of manual operations consolidates the assumption: the line is semi-automatic and must be upgraded to a fully automatic line. Indeed, at the original stage, the line has a certain degree of automation that requires a compromise between manual and automatic operations.

\section{The Problem}

Companies adopt strategies to raise their production rates while reducing the costs. One of the ways to perform that is to reduce labour costs, especially whose who have repetitive tasks. Unlike the general opinion, cost reduction with employees does not mean the dismissal of the worker, but somehow a growth possibility for the worker, assuming new tasks with higher added-value through adequate formation plans. A lot of advantages are available both for the company and worker.

In order to increase the production rate a strategy for this line migration, which can be defined as semi-automatic, to a fully automated line, was made. At the same time, a zero worker dependency and a standardization of the cycle time should be achieved, in order to reduce the cycle time of product assembly. The implementation of automatic systems where manual intervention exists to complete some tasks is proposed to perform this optimization. Manual feeding of components and the packaging of the final product do not make part of the proposed migration process. To perform the migration process to a fully automated line, it was imperative to execute a survey around the main requirements. As a result of this analysis, several requirements were accounted for. Despite the identification of many detailed requirements, only the main ones were listed:

a) Automatic handling of the vertical wires to the winding station;

b) Automatic handling of the spine to the winding station;

c) Automatic handling of the spine after the previous workstation (hook workstation);

d) Automatic feeding and handling of the lower wire;

e) Final station / Automatic transfer between all stations.

\section{Solutions}

To meet all requirements mentioned before, a strategy was defined for the optimization to be possible. As said before, the line is characterized by having two workers that complete the unfinished tasks of the line and, thus, the design strategy focused on the respective stations. Therefore, the optimization process was divided in two different moments: one in the winding workstation, where the first worker is located and at the staples workstation, where the second worker operates. 


\section{Phase 1-Winding Workstation}

At this station, the worker assembles two components: the vertical wires (vertical workstation) and the central spine (spine workstation). The handling of the two components is also performed by the worker.

Before these two phases and leading to support the manual handling elimination between some workstations, a new layout was set. The spine and vertical wires workstation, which was located outside of the suspension mat assembly process flow is now in a position to improve concepts for handling the components without manual operations.

\section{a) Vertical Wires Automatic Handling to the Winding Station}

A handler was designed between the spine and the winding workstation, aiming to copy the manual handling movements of the suspension mat spine performed by the worker. Indeed, all systems and concepts idealized in the production line to help the optimization of a fully automated line were applied to replicate the same operations performed by the worker. To proceed with the idealized handler concept, it was necessary a study about the best movement sequence between workstations. Special care has been taken to avoid collisions. If in one hand the handler must fulfil the movement sequence, on the other hand it cannot compromise the workstations operation. To complete the task, the handler was assembled in the existing transfer which, in this stage, transfers the product to one more workstation (Figure 3). It is important to remember that, at the beginning, this transfer only carried out the handling between three workstations.

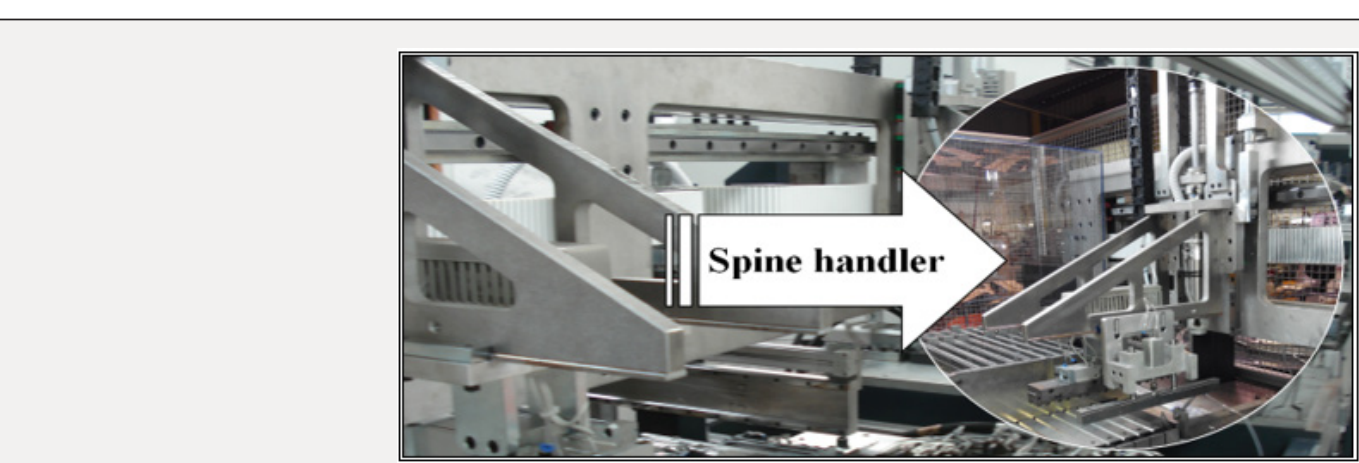

Figure 3: Spine handler assembled in transfer - handler was implemented in the main transfer in order to simplify the number of movements.

\section{b) Spine Automatic Handling to the Winding Station}

Similar attention in handling the vertical wires to the winding workstation was taken. A simple handling system was considered, which follows a "pick \& place" philosophy. This system executes a movement at the same alignment and only has to transport the wire from one location to another. A study was carried out to make the alignment possible and to avoid collisions, aiming to keep the system as simple as possible. Changes in the vertical wires workstation had to be made because the position of the vertical wire is not equal between the two workstations, so this difference could comprise the "pick \& place" philosophy. Changes in the workstation and the automatic handling system of the vertical wires were successfully implemented (Figure 4).

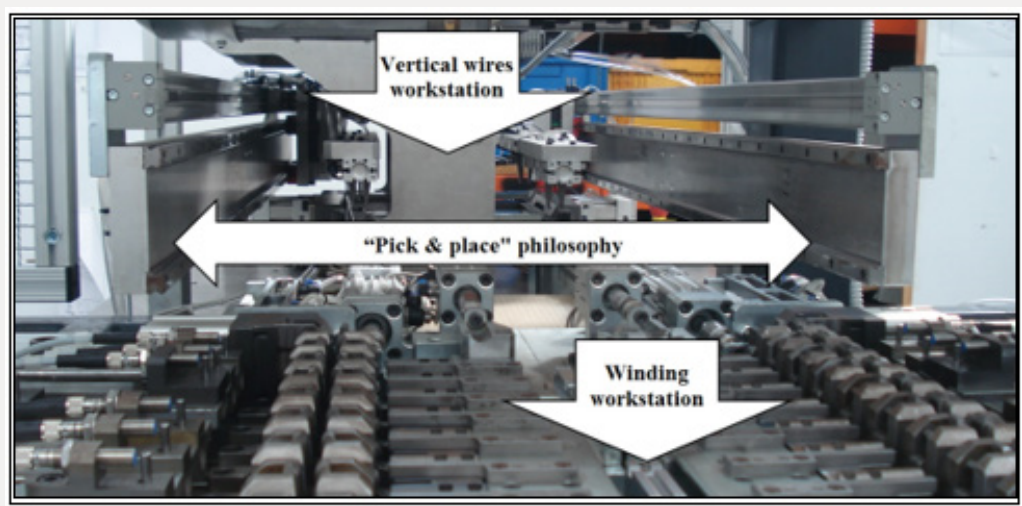

Figure 4: Implemented "Pick \& place" philosophy - it was possible to develop a compact system to connect two workstations with this philosophy (vertical wires and winding workstations).

\section{Phase 2-Staples Workstation}

After the conclusion of the first phase, attention was focused on the second phase. The worker assembles two components in this workstation: the subassembly of the suspension mat arriving 
from the hook workstation and the lower wire. As in the first phase the manual operations carried out by the worker were studied to complete the migration to a fully automated line.

\section{a) Automatic Handling of the Spine after the Previous Workstation (Hook Workstation)}

The communication between the hook and staples workstations was studied in detail. The existing space between the two workstations was eliminated, and an optimized layout was achieved with the removal of this useless area in the line. The staples workstation was moved closer to the hook workstation, and the handling is now made by the main transfer.

\section{b) Automatic Feeding and Handling of the Lower Wire}

At this point, the necessary conditions for the automatic feeding and handling of the lower wire were created. The idealized structure to allocate and feed the lower wire to the line allows the continuity of the line as long as possible. The feeding control is assumed by a system that only provides one lower wire when it is requested. To take the lower wire outside of the feeder area, a table was created below the feeder, which creates the proposed conditions, receiving and moving the lower wire with a linear motion, waiting for its removal. To perform the removal and the transport of the lower wire between the feeder and the final position at the workstation, a handler was idealized. Once again, a "pick \& place" philosophy was adopted, which is the simplest and fastest solution to perform this operation (Figure 5).

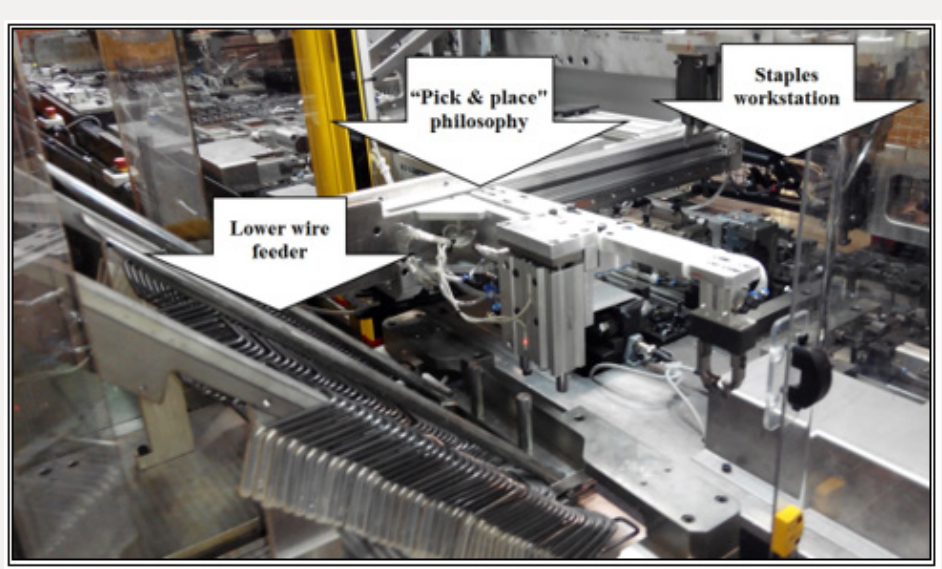

Figure 5: Communication system between workstations - once again "Pick \& place" philosophy was adopted.

At the same time, and to complete the implementation of the lower wire feeding, it was necessary to define the best position for the feeder and handler set. As in the vertical wire workstation, the feeding of the lower wire is perpendicular to the process flow of the suspension mat, hereupon the only decision to be made was to move the feeder and handler to the front or to the back of staples workstation. Trying to avoid collisions with a pair of automatic staplers existing in the station, and to keep the system as simple as possible, the feeder and handler set was placed at the front of the workstation.
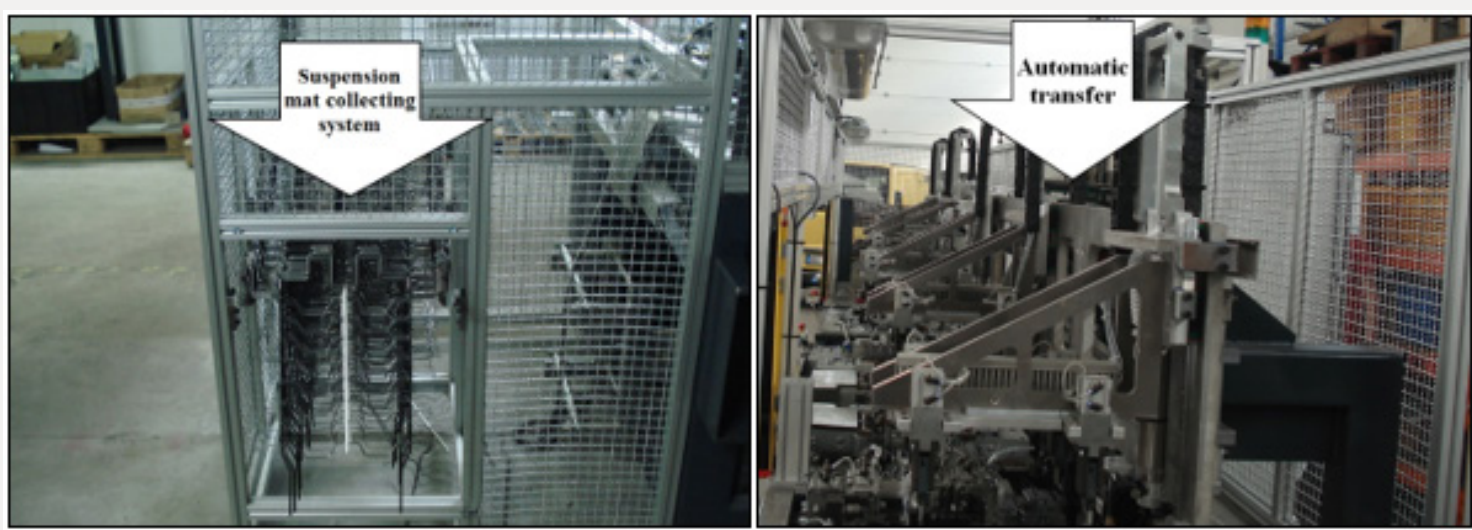

Figure 6: Applied concepts in the final station: a) Suspension mat collecting system at the final workstation; b) Automatic transfer between workstations.

\section{c) Final Station / Automatic Transfer Between All Stations}

At the final of the suspension mat assembly, necessary conditions to remove the final set were created. After the staples workstation, a new station was implanted aiming to receive and collect a number of final suspension mat (Figure 6). In order to avoid mechanical or pneumatic support and using only gravity to move 
the suspension mat, a simple structure was designed. To handle the complete suspension mat to the final station a handler was used as the existing ones in the transfer. The transfer is now able to handle the suspension mat between all workstations. Indeed, the line was successfully migrated to a fully-automated line with the idealized solutions.

\section{Conclusion}

The idealized concepts described in the case study have been useful to achieve the proposed goals and helped the complete migration for a fully-automatic line. The proposed solutions were based on careful studies on the worker movements, especially in the handling operations. At the same time, the studies executed before the improvements of the final solutions avoid situations like collisions that could compromise the project implementation. Besides the automation be an area with relative complexity, it was possible to prove that with simple concepts it is possible to solve problems that originally seemed complicated. Indeed, was possible to improve the level of automation and increased the productivity of the line using low cost and simple solutions. The cost/benefit ratio of the solutions is quite important for the final decision. With the replacement of the manual operations by simple and automatic systems, it was possible to transform an inadequate behaviour on the flow process registered in the initial production line scenario in a stable and fluid process, eliminating, among others, possible stops due to lack of materials.

As every automatic migration process, a strategy must be chosen and one of the key points that are questioned is the elimination of the human resources. The elimination of manual stations and the replacement of manual by automatic operations do not imply the dismissal of the worker from the company. Actually, this is an opportunity for both the workers and the company. The worker assumes new functions with higher value and the company benefits by keeping the worker away from repetitive tasks and movements that could be easily replaced by automatic systems. Regarding the new production system now developed, it is expected an increase in the production rate of about $18 \%$, a completely cut of the human labour costs and an increase in the quality level of around 15\%. The payback time was estimated in 21 months, i.e., clearly shorter than the expected lifetime expected of the product (about 60 months for this model).

\section{Acknowledgment}

$$
\text { ISEP - School of Engineering, Polytechnic of Porto, CIDEM }
$$

\section{References}

1. M Holweg (2008) The evolution of competition in the automotive industry, Build to Order: The Road to the 5-Day Car p.13-34.

2. SJ Hu (2013) Evolving Paradigms of Manufacturing: From Mass Production to Mass Customization and Personalization. Forty Sixth CIRP Conference on Manufacturing Systems 7: 3-8.
3. L. Ribeiro, J Barata (2011) Re-thinking diagnosis for future automation systems: An analysis of current diagnostic practices and their applicability in emerging IT based production paradigms. Computers in Industry 62(7): 639-659.

4. H Schleich, J Schaffer, LF Scavarda (2007) Managing complexity in automotive production, $19^{\text {th }}$ International Conference on Production Research, Valparaiso, Chile.

5. Y He, ML Smith, RA Dudek (2010) Robotic material handler scheduling in flexible manufacturing systems for mass costumization. Robotics and Computer-Integrated Manufacturing 26(6): 671-676.

6. E Carpanzano, F Jovane (2007) Advanced Automation Solutions for Future Adaptive Factories. Annals of the CIRP 56(1): 435-438.

7. A Lešková, L Kováčová (2012) Automotive supply chain outline. Electronic journal Perner's contacts 7(2): 96-104.

8. S Serdar-Asan (2011) A review of supply chain complexity drivers, Proceedings of the $41^{\text {st }}$ International Conference on Computers \& Industrial Engineering, pp.792-797.

9. SA Darestani, Y Ismail, N Ismail, RM Yusuff (2010) An Investigation on Supplier Delivery Performance by using SPC Techniques for Automotive Industry. Journal of American Science 6(4): 5-11.

10.S de Treville, RD Shapiro, AP Hameri (2004) From supply chain to demand chain: the role of lead time reduction in improving demand chain performance. Journal of Operations Management 21(6): 613-627.

11. Mishina K (1995) Toyota Motor Manufacturing. Harvard Business School, case 9-693-019, USA.

12. HB Lary (1968) Imports of Manufactures from Less Developed Countries - Trade in Labor-Intensive Manufactures. National Bureau of Economic Research pp. 86-115.

13.L Kromann, JR Skaksen (2011) A Sørensen Automation, labor productivity and employment-a cross country comparison, CEBR, Copenhagen Business School.

14.JZ Bloom, IJ Lambrechts, NJ le Roux (1998) Distinguishing between capital intensive and labour intensive enterprises listed in the industrial sector of the JSE. Management Dynamics 7(4): 39-68.

15. K eldmann, B Mutter, T Haselrnann (1999) Automated Assembly of Lightweight Automotive Components. Annals of CIRP 48(1): 9-12.

16. Jaakko Peltokorpi, Mika Lohtander, Sampsa V, A Laakso (2014) Effective relationships of factors in a manual assembly line environment. Int J of Engineering Management and Economics 4(3-4): 267-290.

17. Sandra Maattsson (2013) What is perceived as complex in final assembly? Licenciate Thesis, Chalmers University of Technology, Gothenburg, Sweden.

18. G Michalos, S Makris, N Papakostas, D Mourtzis, G Chryssolouris (2010) Automotive assembly technologies review: Challenges and outlook for a flexible and adaptive approach. CIRP Journal of Manufacturing Science and Technology 2(2): 81-91.

19. F Jovanel, Y Koren, CR Boër (2003) Present and Future of Flexible Automation: Towards New Paradigms. CIRP Annals - Manufacturing Technology 52(2): 543-560.

20. RS Wadhwa (2012) Flexibility in manufacturing automation: A living lab case study of Norwegian metalcasting SMEs. Journal of manufacturing Systems 31(4): 444-454.

21. SL Hunter (2001-2002) Ergonomic Evaluation of Manufacturing systems Designs. Journal of Manufacturing Systems 20(6): 429-444.

22. PMS Nunes, FJG Silva (2013) Advances in Sustainable and Competitive Manufacturing Systems. 23 ${ }^{\text {rd }}$ International Conference on Flexible Automation and Intelligent Manufacturing, pp. 329-340.

23. L. Morello, LR Rossini, G Pia, A Tonoli (2011) The Automotive BodyVolume I: Components Design, Springer, Cap.6, pp. 560-603. 
(C) (i) This work is licensed under Creative Commons Attribution 4.0 License

To Submit Your Article Click Here: Submit Article

DOI: 10.32474/ARME.2018.01.000102

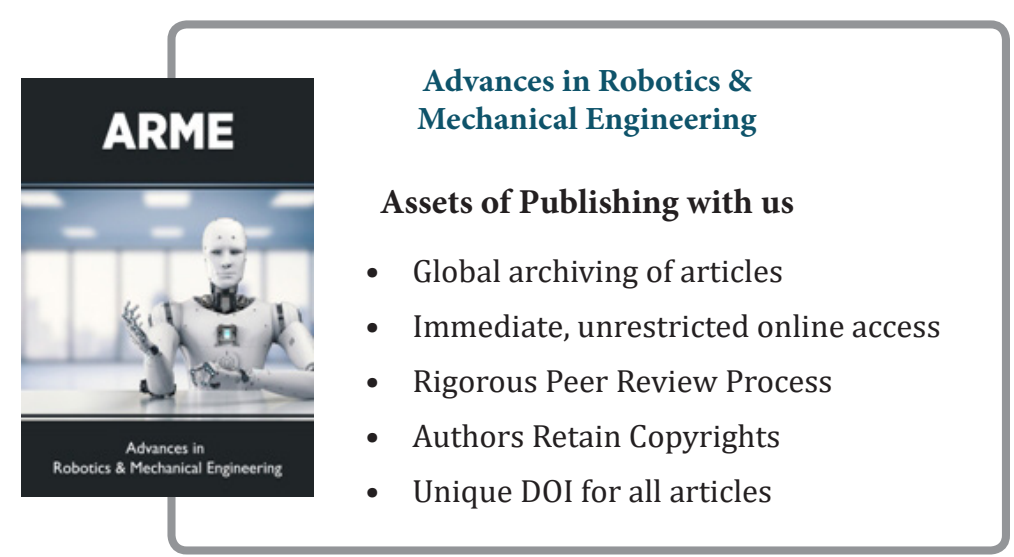

